\title{
A Case Report of Coronary Fistula with ST Segment Elevation Myocardial Infarction
}

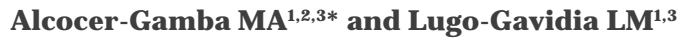 \\ ${ }^{1}$ Autonomous University of Queretaro, Mexico \\ ${ }^{2}$ Department of Interventional Cardiology, Instituto de \\ Corazon de Querétaro, México \\ ${ }^{3}$ Research Department Centro de estudios clínicos de \\ Querétaro, México \\ *Corresponding author: Marco Antonio Alcocer \\ Gamba, Department of Interventional Cardiology, \\ Instituto de Corazon de Querétaro, Universidad \\ Autónoma de Querétaro, Prolongación Ignacio Zaragoza \\ \#16-B Col, Centro CP 76180, México
}

Received: November 30, 2016; Accepted: J anuary 12, 2017; Published: J anuary 18, 2017

\begin{abstract}
A patient presented with a ST Segment Elevation Myocardial Infarction (STEMI). The Coronarography revealed multivessel disease and the emergence of a coronary fistula that is directed towards the aorta. The culprit vessel was treated with primary percutaneous coronary intervention with subsequent treatment with coronary artery bypass graft surgery.

Keywords: Coronary fistula; Myocardial infarction
\end{abstract}

\section{Case Presentation}

A 61-year-old male presented with burning chest pain of medium intensity, diaphoresis, dyspnea and evacuation desire, the electrocardiogram revealed sinus rhythm with first degree atrioventricular block and ST Segment Elevation, positive cardiac biomarkers, confirming the diagnosis of ST Segment Elevation Myocardial Infarction (STEMI).

Patient underwent urgent coronary angiography that revealed Right Coronary Artery (RCA) with total thrombotic occlusion in the proximal-middle segment; it was observed an abnormal vessel with independent origin just above the ostium of the RCA, directed towards the aorta (Figure 1).

Left main with $50 \%$ distal obstruction, circumflex artery presents a tandem lesions on a marginal branch of $80 \%$, Left Anterior Descending (LAD) with proximal ectasia and severe diffuse lesions in the proximal and middle segments (90\%) and was observed the emergence of great caliber vessel through proximal ectasia and that is directed towards the aorta (coronary fistula) (Figure 2).

It was decided to perform the primary coronary intervention (p-ICP) of the culprit vessel, RCA lesion was managed by thromboaspiration and a subsequent stenting, being necessary to splice from distal to proximal 3 Bare Metal Stents (BMS), with $0 \%$ of residual lesion confirmed by stent boost technique, with presence of epicardial TIMI III flow and no complications (Figure 3).

Two weeks later a coronary CT was performed to evaluate the fistula anatomy reconstruction finding a vessel of $1.7 \mathrm{~mm}$ of diameter and the origin at $8 \mathrm{~mm}$ from de ostium directed through aorta (Figure $4)$.

Patient was programmed after a one month of the acute event for subsequent Coronary Artery Bypass Graft surgery (CABG) for coronary revascularization with left internal mammary artery to $L A D$, inverted saphenous venous hemoducts to the marginal branch and closure of the left fistula, five days before the intervention ticagrelor was stopped and continued taking aspirin, and following CABG he started taking clopidogrel.

\section{Discussion}

Coronary fistula is an abnormality characterized by abnormal communication between a coronary artery and a cardiac chamber, the systemic or pulmonary circulation. 55\% of fistulas originate from the right coronary artery, $35 \%$ of the left coronary artery and less than $10 \%$ of both $[1,2]$.

In general, they are asymptomatic (40\%), large fistulas (3 times the size of the coronary artery) can become symptomatic and can cause coronary artery steal phenomenon, which leads to ischemia of the segment of myocardium perfused by the coronary artery. The pathophysiological mechanism of coronary artery fistula is myocardial stealing phenomenon or reduction in myocardial blood flow distal to the site of the coronary artery fistula connection [3].

There is no consensus as to the indications for surgical or endovascular correction of coronary fistulas, the recommendation is to individualize in each case. The therapeutic decision should focus on the evaluation of the hemodynamic repercussion and

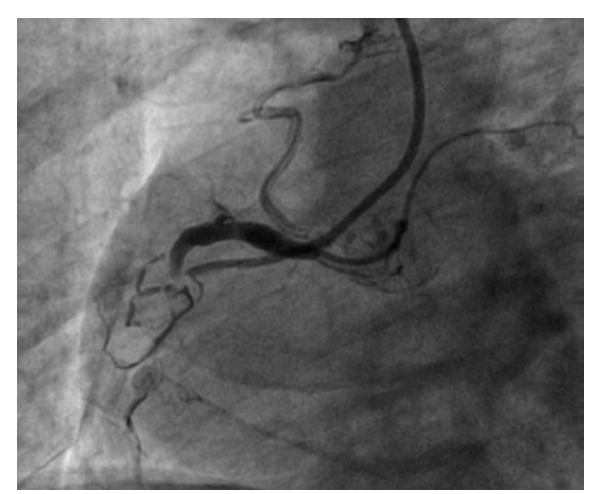

Figure 1: Right Coronary Artery (RCA) with total thrombotic occlusion in the proximal-middle segment with an abnormal vessel directed towards the aorta.
Austin J Clin Cardiolog - Volume 4 Issue 1 - 2017 ISSN : 2381-9111 | www.austinpublishing group.com Alcocer-Gamba et al. (C) All rights are reserved
Citation: Alcocer-Gamba MA and Lugo-Gavidia LM. A Case Report of Coronary Fistula with ST Segment Elevation Myocardial Infarction. Austin J Clin Cardiolog. 2017; 4(1): 1053. 


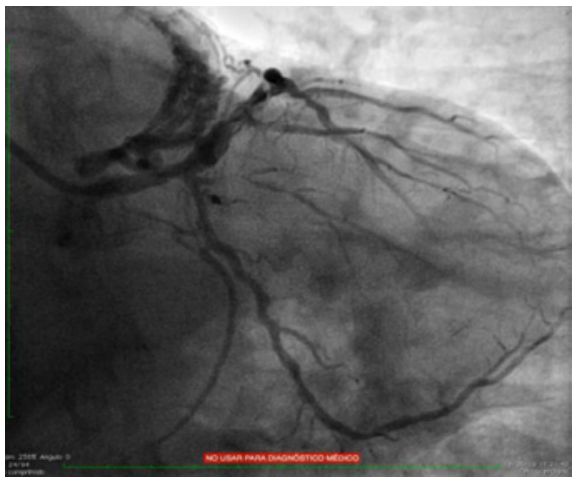

Figure 2: Left coronary artery with proximal ectasia, multivessel disease and emergence of great caliber vessel directed towards the aorta.

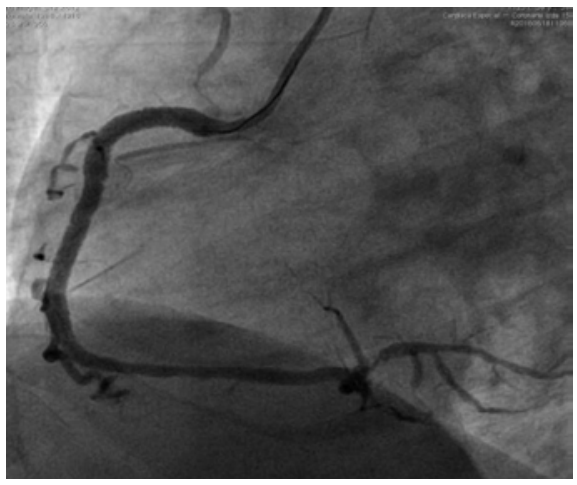

Figure 3: Angiographic result after $\mathrm{p}-\mathrm{PCl}$ of RCA lesion.

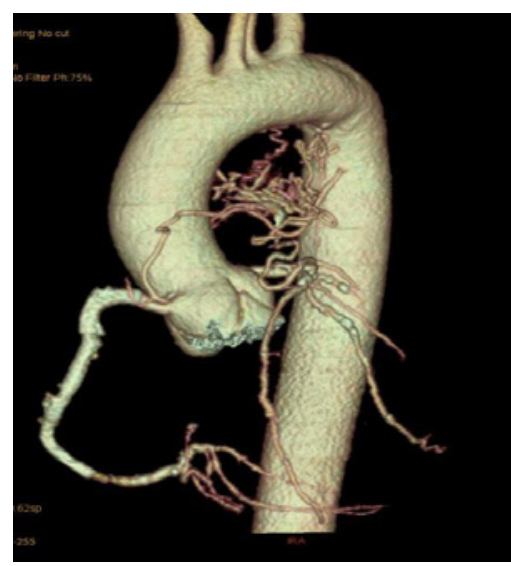

Figure 4: CT Reconstruction, it revealed a vessel of $1.7 \mathrm{~mm}$ of diameter and the origin at $8 \mathrm{~mm}$ from de ostium directed through aorta.

focus on preserving the coronary flow. Treatment includes ligation, embolization, placement of Coils and coated stents [4-8].

In the site of a STEMI p-PCI has become the treatment of choice, multi-vessel coronary artery disease is found to be present from 41 to $67 \%$ of patients, [9-12] and it has been found to be associated with worse prognosis in patients with STEMI [13] there are different strategies to treat this patients including revascularization of single vessel disease, p-PCI of infract related artery only, primary multivessel PCI and subsequent staged PCI or CABG. The precise timing of bypass surgery for the stable patient with indications for surgery remains controversial [14] current guidelines recommend delaying surgery 4 to 6 weeks after BMS placement to allow proper thienopyridine use to reduce the risk of coronary stent thrombosis [15-17]. It had been reported an incidence of 30-day ischemic events of $2.6 \%$ in patients with Bare Metal Stent (BMS) when the interval between stent insertion and major elective cardiac surgery was 45 to 180 days and $6.7 \%$ when the interval was $<45$ days and $20 \%$ in patients with Drug Eluting Stent (DES) implantation when the interval between stent insertion and surgery was $<45$ days, whereas the event rate was only $1.2 \%$ once the interval exceeded 180 days [18].

\section{Conclusion}

Coronary fistula is a rare congenital malformation, the diagnosis of which arises as a clinical finding. In the present case, the patient's coronary artery disease together with obstruction and coronary steal phenomenon represent a pathophysiological problem. It is essential to individualize each case to determine the appropriate therapy to follow.

\section{References}

1. Levin D, Fellows KE, Abrams HL. Hemodynamically significant primary anomalies of the coronary arteries. Angiographic aspects. Circulation. 1978; 58: 25-34.

2. Takeuchi N, Takada M, Nishibori Y, Maruyama T. A case Report of coronary arteriovenous fistula with an unrupted coronary artery aneurysm successfully treated by surgery. Case Report in Cardiology. 2012; 314685: 6.

3. Schamroth C. Coronary artery fistula. J Am Coll Cardiol. 2009; 53: 523.

4. Effler D, Sheldon W, Turner J, Groves L. Coronary arteriovenous fistulas: diagnosis and surgical management. Report of fifteen cases. Surgery. 1967; 61: 41-50.

5. Mangukia CV. Coronary artery fistula. Ann Thorac Surg. 2012; 93: 20842092.

6. Latson LA, Forbes TJ, Cheatham JP. Transcatheter coil embolization of a fistula from the posterior descending coronary artery to the right ventricle in a two-year-old child. Am Heart J. 1992; 124: 1624-1626.

7. Moskowitz WB, Newkumet KM, Albrecht GT, Goble MM, Schieken RM. Case of steel versus steal: coil embolization of congenital coronary arteriovenous fistula. Am Heart J. 1991; 121: 909-911.

8. Reidy JF, Tynan MJ, Qureshi S. Embolization of a complex coronary arteriovenous fistula in a 6 year old child: the need for specialised embolisation techniques. Br Heart J. 1990; 63: 246-248.

9. Cardarelli F, Bellasi A, Fang-Shu Ou, Shaw LJ, Veledar E, Roe MT, et al. Combined impact of age and estimated glomerular filtration rate on in-hospital mortality after percutaneous coronary intervention for acute myocardial infarction (from the American College of Cardiology National Cardiovascular Data Registry). Am J Cardiol. 2009; 103: 766-771.

10. Jang $H$, Hun S, Shung $C$, Yongkeun $C$, Dong $H$, et al. Acute Myocardial Infarction Registry Investigators. Predictors of six-month major adverse cardiac events in 30-day survivors after acute myocardial infarction (from the Korea Acute Myocardial Infarction Registry). Am J Cardiol. 2009; 104: 182189.

11. Rasoul S, Ottervanger JP, De Boer MJ, Dambrink JHE, Hoorntje JCA Gosselink ATM, et al. Predictors of 30-day and 1-year mortality after primary percutaneous coronary intervention for ST-elevation myocardial infarction. Coron Artery Dis. 2009; 20: 415-421.

12. Toma M, Buller CE, Westerhout CM, Fu Y, O'Neill WW, Holmes DR, et al. Nonculprit coronary artery percutaneous coronary intervention during acute ST-segment elevation myocardial infarction: insights from the APEX-AMI trial. Eur Heart J. 2010; 31: 1701-1707. 
13. Jaski BE, Cohen JD, Trausch J, Marsh DG, Bail GR, Overlie PA, et al Outcome of urgent percutaneous transluminal coronary angioplasty in acute myocardial infarction: comparison of single-vessel versus multivessel coronary artery disease. Am Heart J. 1992; 124: 1427-1433.

14. Hochberg MS, Parsonnet V, Gielchinsky I, Hussain SM, Fisch DA, Norman JC. Timing of coronary revascularization after acute myocardial infarction. Early and late results in patients revascularized within seven weeks. J Thorac Cardiovasc Surg. 1984; 88: 914-921.

15. R Raghavan, BS Benzaquen, L Rudski. Timing of bypass surgery in stable patients after acute myocardial infarction. Can J Cardiol. 2007; 23: 976-982.

16. Fleisher LA, Beckman JA, Brown KA, et al. American College of Cardiology; American Heart Association Task Force on Practice Guidelines (writing Committee to Revise the 2002 Guidelines on Perioperative Cardiovascular Evaluation for Noncardiac Surgery); American Society of Echocardiography; American Society of Nuclear Cardiology; Heart Rhythm Society; Society of Cardiovascular Anesthesiologists; Society for Cardiovascular Angiography and Interventions; Society for Vascular Medicine and Biology; Society for Vascular Surgery. ACC/AHA 2007 guidelines on perioperative cardiovascular evaluation and care for noncardiac surgery: a report of the American College of Cardiology/American Heart Association Task Force on Practice Guidelines (Writing Committee to Revise the 2002 Guidelines on Perioperative Cardiovascular Evaluation for Noncardiac Surgery) developed in collaboration with the American Society of Echocardiography, American Society of Nuclear Cardiology, Heart Rhythm Society, Society of Cardiovascular Anesthesiologists, Society for Cardiovascular Angiography and Interventions, Society for Vascular Medicine and Biology, and Society for Vascular Surgery. Circulation. 2007; 116: 1971-1996.

17. Capodanno D, Angiolillo DJ. Management of Antiplatelet Therapy in Patients With Coronary Artery Disease Requiring Cardiac and Noncardiac Surgery. Circulation. 2013; 128: 2785-2798.

18. Wijeysundera DN, Wijeysundera HC, Yun L, Wąsowicz M, Beattie WS, Velianou JL, et al. Risk of elective major noncardiac surgery after coronary stent insertion: a population-based study. Circulation. 2012; 126: 1355-1362.
Austin J Clin Cardiolog - Volume 4 Issue 1 - 2017

ISSN : 2381-9111 | www.austinpublishinggroup.com

Alcocer-Gamba et al. (C) All rights are reserved
Citation: Alcocer-Gamba MA and Lugo-Gavidia LM. A Case Report of Coronary Fistula with ST Segment Elevation Myocardial Infarction. Austin J Clin Cardiolog. 2017; 4(1): 1053. 